\title{
2-dimensional Mapping of Sulfur Dioxide and Bromine Oxide at the Sakurajima Volcano with a Ground Based Scanning Imaging Spectrograph System
}

\author{
Hanlim Lee and Jhoon Kim* \\ Department of Atmospheric Sciences, Yonsei University, Seoul 120-749, Korea \\ Jaeyong Ryu \\ Korea Environmental Industry and Technology Institute (KEITI), Seoul 122-706, Korea \\ Soonchul Kwon \\ School of Civil and Environmental Engineering, Georgia Institute of Technology, Atlanta 30332, USA \\ Youngmin Noh and Myojeong Gu \\ Department of Environmental Science and Engineering, Gwangju Institute of Science and \\ Technology (GIST), Gwangju 500-712, Korea
}

(Received June 24, 2010 : revised August 17, 2010 : accepted August 23, 2010)

\begin{abstract}
A scanning imaging spectrograph system was used in this study to retrieve readings of the 2-D distribution of $\mathrm{SO}_{2}$ and $\mathrm{BrO}$ around the crater of the Sakurajima volcano in Japan. The measurement was carried out during the daytime on November 2, 2005. Measurements were made at the surface of the site, located $5 \mathrm{~km}$ from the Sakurajima crater. One hundred horizontal scans were performed. Each column scanned by the system consists of 64 vertical pixels in order to retrieve the spatial distributions of $\mathrm{BrO}$ and $\mathrm{SO}_{2}$ in the plume in terms of slant column densities (SCDs). Measured spectra were analyzed to identify and quantify $\mathrm{SO}_{2}$ and $\mathrm{BrO}$ in the volcanic plume utilizing the plume's specific absorption features in the ultra violet region. Two-dimensional $\mathrm{BrO}$ and $\mathrm{SO}_{2}$ distributions in $\mathrm{SCD}$ were retrieved horizontally covering the upwind, crater and downwind areas, and vertically, including the plume in the center of the scanned image. Both horizontal and vertical dispersions of $\mathrm{SO}_{2} \mathrm{SCD}$ from the crater were successfully measured to be from $10^{17}$ to $4.5 \times 10^{18}$ molecules $\mathrm{cm}^{-2}$. However, BrO was measured below $10^{15}$ molecules $\mathrm{cm}^{-2}$, which is considered its background level.
\end{abstract}

Keywords: Sulfur dioxide, Bromine oxide, DOAS, Two-dimensional mapping

OCIS codes : (280.0280) Remote sensing; (280.1120) Air pollution monitoring

\section{INTRODUCTION}

The Eyjafjallajokull volcano in Iceland recently erupted causing immense disruption in air traffic all over Europe and injecting ash, dust, and gases into the atmosphere. Sulfur dioxide $\left(\mathrm{SO}_{2}\right)$ in particular, is one of the major volcanic trace gases, causes acid rain and is a key precursor for sulfuric acid aerosol formation. The sulfuric aerosols may be present in the stratosphere for weeks and can be transported to other continents. $\mathrm{SO}_{2}$ is also known to have adverse effects on human health.

Volcanic eruptions are known to be a major source of reactive halogen species, which are associated with the destruction of $\mathrm{O}_{3}$ in the vicinity of volcanic areas. Volcanic emission contains reactive halogen species such as $\mathrm{HCl}$ and $\mathrm{HF} . \mathrm{BrO}$ is also one of the major volcanic halogen species observed in recent studies. $\mathrm{BrO}$ was observed in a volcanic plume at the Soufriere Hills volcano on Monstserrat in May 2002 [1]. BrO has also been observed at other volcanoes where the measurements were carried out $1 \mathrm{~km}$

\footnotetext{
*Corresponding author: jkim2@yonsei.ac.kr

Color versions of one or more of the figures in this paper are available online.
} 
from the emission source.

Accurate measurement of volcanic gas emission is important since these gases affect atmospheric chemistry in the vicinity of a volcano. Remote sensing techniques have recently been preferred for volcanic gas measurements, given the inaccessibility of volcanic craters. A variety of volcanic gases such as $\mathrm{BrO}[1-2]$ and $\mathrm{ClO}$ [2] have been investigated with the Multi Axis (MAX)-Differential Optical Absorption Spectroscopy (DOAS) technique. $\mathrm{SO}_{2}$ and $\mathrm{BrO}$ abundances as a function of the distance from the source were studied by ground-based scattered light MAX-DOAS in Mt. Etna, Italy [3]. Additionally, $\mathrm{BrO}$ to $\mathrm{SO}_{2}$ ratios for various volcanic sites were investigated by the same study [4]. While the MAX-DOAS measurement obtains the vertical distribution of trace gases, the passive imaging spectrograph [5-6], which uses a two-dimensional array detector, allows one to retrieve two-dimensional spatial distribution measurements of atmospheric trace gases [7-9]. However, there have been few studies [3] that demonstrated the capability of the passive imaging spectrograph technique to retrieve 2-D distributions of $\mathrm{SO}_{2}$, while most previous studies focused on $\mathrm{NO}_{2}$ distributions at various measurement sites [7-9]. Therefore, uncertainties remain regarding the capability of the retrieval of $2 \mathrm{D}$ distributions of $\mathrm{SO}_{2}$ using the imaging spectrograph technique at other $\mathrm{SO}_{2}$ and $\mathrm{BrO}$ absorption wavelengths. In addition, a previous study [3] discussed the need for further validation using different absorption wavelengths (e.g., 312.1 to $321.5 \mathrm{~nm}$ and 316.3 to $327.5 \mathrm{~nm}$ used for $\mathrm{SO} 2$ and $\mathrm{BrO}$ retrieval, respectively, in the present study) in investigating the capability of the imaging spectrograph system for the retrieval of $2 \mathrm{D}$ distributions of $\mathrm{SO}_{2}$ and BrO. This present work is part of a wider effort to gather information on the vertical and horizontal distribution of $\mathrm{SO}_{2}$ and halogen gases around the crater of Sakurajima volcano in Japan using remote sensing techniques. This study presents two-dimensional distributions of $\mathrm{SO}_{2}$ and $\mathrm{BrO}$ around the top of the Sakurajima volcano in Japan.

\section{MEASUREMENT AND RESULTS}

Fig. 1 shows the passive scanning imaging spectrograph system developed by Gwangju Institute of Science and Technology (GIST). The system uses scattered sunlight as a light source. The system contains an imaging spectrometer coupled with a two-dimensional CCD detector for recording scattered sunlight intensity as a function of wavelength. The scattered sunlight at each azimuth angle can be measured by the system equipped with a horizontally moving mirror.

The system consists of the light collecting component, a spectrometer, a 2-D CCD detector, and a system controller. The light collecting component is composed of a moving mirror and a quartz lens (plano convex: $\mathrm{f}=100 \mathrm{~mm}, \varnothing=$ $25.4 \mathrm{~mm}$ ). The mirror, combined with a stepper motor, is used to aim and scan the area of interest and reflects scattered sunlight, which has transferred through the target area, onto the lens. The incoming light is focused on to the entrance aperture of the spectrometer (Triax 180; Czerny Turner type, F/\# 3.9, Horiba Jobin Yvon Inc., Edison, USA). The flat holographic grating (1200 grooves $\mathrm{mm}^{-1}$; blazed at $330 \mathrm{~nm}$ ) in the spectrometer disperses the light which is then focused onto a two-dimensional CCD chip ( $26.6 \times 6.9 \mathrm{~mm}$ in size corresponding to $2048 \times 512$ pixels) on a detector head. The 512 CCD rows were binned in groups of 8 , yielding 64 rows for the spatial distribution in order to minimize the cross-talk effect between vertical pixels that might be caused by the finite point spread function. The horizontal 2048 pixels are served as a spectral dispersion axis while 64 vertical pixels represent the spatial distribution. The slit functions of full width half maximum (FWHM) were 0.3 and $0.6 \mathrm{~nm}$ at the center and the edge of the focal plane respectively as the alignment of the 2-D CCD detector was optimized for both the center wavelength and the center row.

LabVIEW software was utilized to control the scanning mirror directions and the CCD shutter. To reduce temperature changes that might have led to variations in instrumental function during field measurements (e.g., spectral resolution and wavelength range), nine Peltier elements $(40 \times 40 \times$ $4 \mathrm{~mm}$ ) were attached to the base plate of the system spectrograph. The temperature inside the instrument was kept at $5^{\circ} \mathrm{C}$; less than $\pm 0.1^{\circ} \mathrm{C}$ variation in temperature was recorded during the measurement period. The spectrograph was thermally isolated from the entrance optics by inserting a quartz focusing lens between the entrance optics and one side of the foil-covered aluminum box that contained the spectrograph and scanning mirror; this ensured that the air temperature in the box could be controlled. The CCD chip was cooled down to $-70^{\circ} \mathrm{C}$ to minimize the dark current in the $\mathrm{CCD}$ detector.

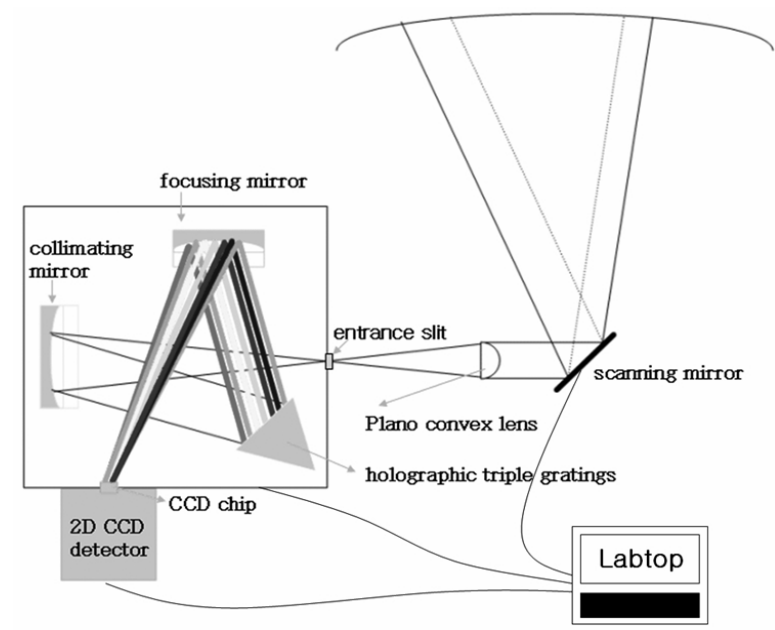

FIG. 1. Instrument setup for scanning imaging spectrograph measurements, consisting of a scanning mirror, a focusing lens, and a Czerny turner design imaging spectrograph with a two-dimensional CCD detector. 
The field measurement site and its surrounding area are described in Fig. 2. The system was installed on the rooftop of a disaster prevention facility at a distance of $5.14 \mathrm{~km}$ east $\left(31.34^{\circ} \mathrm{N}, 130.39^{\circ} \mathrm{E}\right)$ of the Sakurajima volcano crater in Japan. None of the major anthropogenic $\mathrm{SO}_{2}$ sources were present on the line of instrumental sight between the system and the target crater. The measurements were conducted from October 17 to November 2, 2005. However, this study focuses on the results obtained from 11:20 a.m. until 11:30 a.m. local time on November 2 as this time was marked by a clear sky. The time taken for the acquisition of a complete image was $3 \mathrm{~min}$ during the measurement period. During the measurement period the wind was moderate, blowing from the southwest at $2.8 \mathrm{~m} \mathrm{~s}^{-1}$. The ambient temperature was $16^{\circ} \mathrm{C}$. The moving mirror was directed to the center of the crater, and sequentially scanned the crater area from southeast to northwest (Fig. 2).

The collected scattered sunlight signals were analyzed using WinDOAS software, which is based on the DOAS technique [10]. The dark current and offset signals of the spectrograph were removed from each of the measured spectra using the spectra taken with the same measurement parameters under the condition of no light entering the instrument entrance slit. Given the wind direction, the spectra taken on the rightmost column on the area of interest was used as a Fraunhofer reference spectrum (FRS). The contributions of background $\mathrm{SO}_{2}$ and $\mathrm{BrO}$, including both stratospheric and tropospheric signals, were eliminated by dividing the measured spectra by the FRS on the same row in the CCD chip. Mapping wavelength information onto the CCD pixels was done by the optical density fitting of the convoluted FRS to a hyper-spectral Fraunhofer spectrum reference [11]. Ring spectra were calculated from the individual FRS using DOASIS software in order to

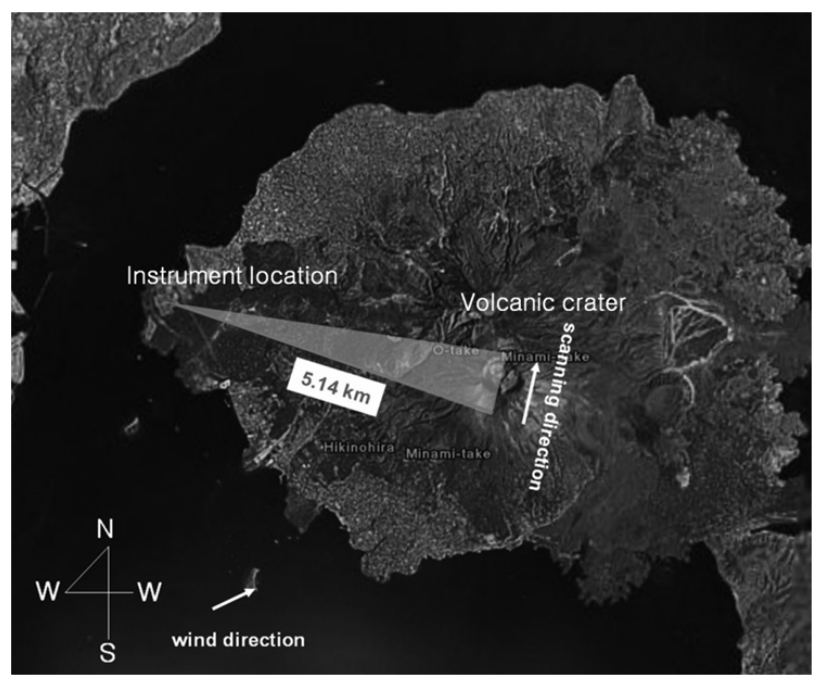

FIG. 2. Location of scanning imaging spectrograph setup and the Sakurajima volcanic crater. The solid arrow indicates the scanning direction of the instrument. account for the Ring effect [12], which denotes the fillingin of Fraunhofer lines. The retrieved quantities from scanning imaging spectrograph measurements are expressed as slant column density (SCD).

$$
S C D=\int_{0}^{Z} C(l) d l=\bar{C} Z
$$

Where $\mathrm{C}$ and $\bar{C}$ denotes a concentration of a species and the average concentration over an absorption light path length $(Z)$ between the instrument and a location where the instrument can detect. Absorption cross sections of gases are usually convoluted with an instrumental slit function in order to account for the spectral resolution of the measured spectrum. The convolution of a spectrum $I$ by a slit function $F$ is given by the following equation.

$$
S\left(\lambda_{0}\right)=\int I(\lambda) \cdot F\left(\lambda-\lambda_{0}\right) d \lambda
$$

Where $S$ and $\lambda$ denote a convoluted gas spectrum and wavelength, respectively. The equation is calculated by decomposition of the surface area into trapezoids. The integral interval is defined by the width of the slit function (FWHM). For retrieval of $\mathrm{SO}_{2}$ differential slant column densities (SCDs), absorption cross sections of $\mathrm{SO}_{2}, \mathrm{NO}_{2}, \mathrm{O}_{3}, \mathrm{ClO}$, and $\mathrm{BrO}$ were convoluted with individual slit functions determined for the binned row of the CCD chip and fitted with the calculated Ring spectrum and a fifth-order polynomial to the measured spectra between 312.1 and 321.5 $\mathrm{nm}$ as shown in Fig. 3. For retrieval of BrO SCDs, the

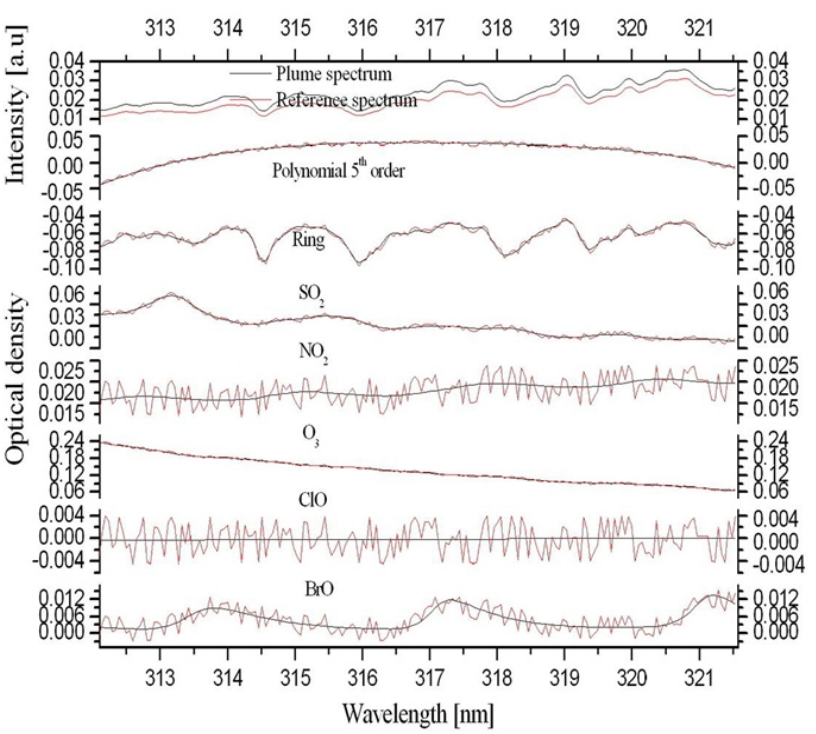

FIG. 3. Example of measured and fitted spectra between 312.1 and $321.5 \mathrm{~nm}$ for evaluating $\mathrm{SO}_{2}$ slant column densities. Black lines represent the absorption signal; red lines represent the sum of the absorption signal and the fit residual. The residual is small compared to $\mathrm{NO}_{2}$ absorption. Intensity is expressed as an arbitrary unit. 
same absorption cross sections used for $\mathrm{SO}_{2}$ retrieval were fitted to the measured spectra but in a different wavelength interval between 316.3 and $327.5 \mathrm{~nm}$ as shown in Fig. 4. Slant column densities can be obtained from the following equation.

$$
\text { Minimize } \chi^{2}=\sum_{\lambda_{1}}^{\lambda_{2}}[K(\lambda)-M(\lambda)]^{2}
$$

Where $K$ denotes a measured spectrum and $M$ denotes a modeled spectrum which is the sum of slant column densities multiplied by the convoluted gas spectra, the Ring spectrum, and a polynomial. The plume spectrum in Fig. 3 and 4 is represented by $K$ while $M$ accounts for the sum of the rest of spectra except for the residual spectra in both figures.

The two-dimensional distributions of the $\mathrm{SO}_{2}$ and $\mathrm{BrO}$ SCDs simultaneously measured by the scanning imaging spectrograph system are presented in Fig. 5(a) and 5(b), respectively. The photograph taken from the instrument site is shown in Fig. 5(c). Each of the images in Fig. 5(a) and $5 \mathrm{~b}$ comprises 100 columns along the azimuth angle, which were sequentially scanned by the moving mirror and 64 rows along the elevation angle, which corresponds to the

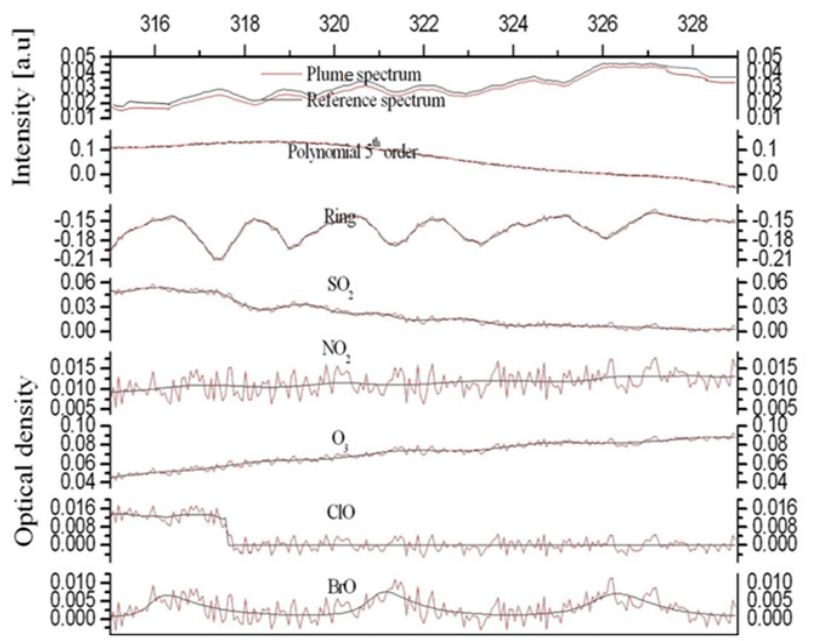

Warelength $[\mathrm{nm}]$

FIG. 4. Example of measured and fitted spectra between 316.3 and $327.5 \mathrm{~nm}$ for evaluating $\mathrm{BrO}$ slant column densities. Black lines represent the absorption signal; red lines represent the sum of the absorption signal and the fit residual. The residual is small compared to $\mathrm{BrO}$ absorption. Intensity is expressed as an arbitrary unit. number of the vertical pixels of the CCD chip. The scanned area was $0.44 \mathrm{~km}$ (vertically) $\times 0.97 \mathrm{~km}$ (horizontally). A single pixel in Fig. 5(a) and 5(b) corresponds to an area of $6.8 \mathrm{~m}$ (vertically) $\times 9.7 \mathrm{~m}$ (horizontally) at the crater location. The $\mathrm{SO}_{2} \mathrm{SCDs}$ range from $10^{17}$ molecules $\mathrm{cm}^{-2}$ to 4.5 $\times 10^{18}$ molecules $\mathrm{cm}^{-2}$ in Fig. 5(a), the fit errors of which correspond to $9.0 \times 10^{15}$ molecules $\mathrm{cm}^{-2}$ and $9.7 \times 10^{16}$ molecules $\mathrm{cm}^{-2}$ in Fig. 6(a). High $\mathrm{SO}_{2} \mathrm{SCD}$ values were found at the crater while $\mathrm{SO}_{2} \mathrm{SCDs}$ decreased with distance from the crater as the evolution of $\mathrm{SO}_{2}$ concentration is dominated by dilution with background air. The $\mathrm{BrO}$ SCDs range from $9.5 \times 10^{13}$ molecules $\mathrm{cm}^{-2}$ to $8.4 \times 10^{14}$ molecules $\mathrm{cm}^{-2}$ in Fig. 5(b), the fit errors of which correspond to $4.8 \times 10^{13}$ molecules $\mathrm{cm}^{-2}$ and $9.1 \times 10^{13}$ molecules $\mathrm{cm}^{-2}$, respectively in Fig. 6(b). Fig. 5(b) shows the decrease of $\mathrm{BrO}$ SCDs as a function of vertical distance from the lowest row to the uppermost row. The vertical characteristics of the $\mathrm{BrO}$ SCD distribution implies $\mathrm{BrO}$ emitted from the volcanic crater was not detected by the

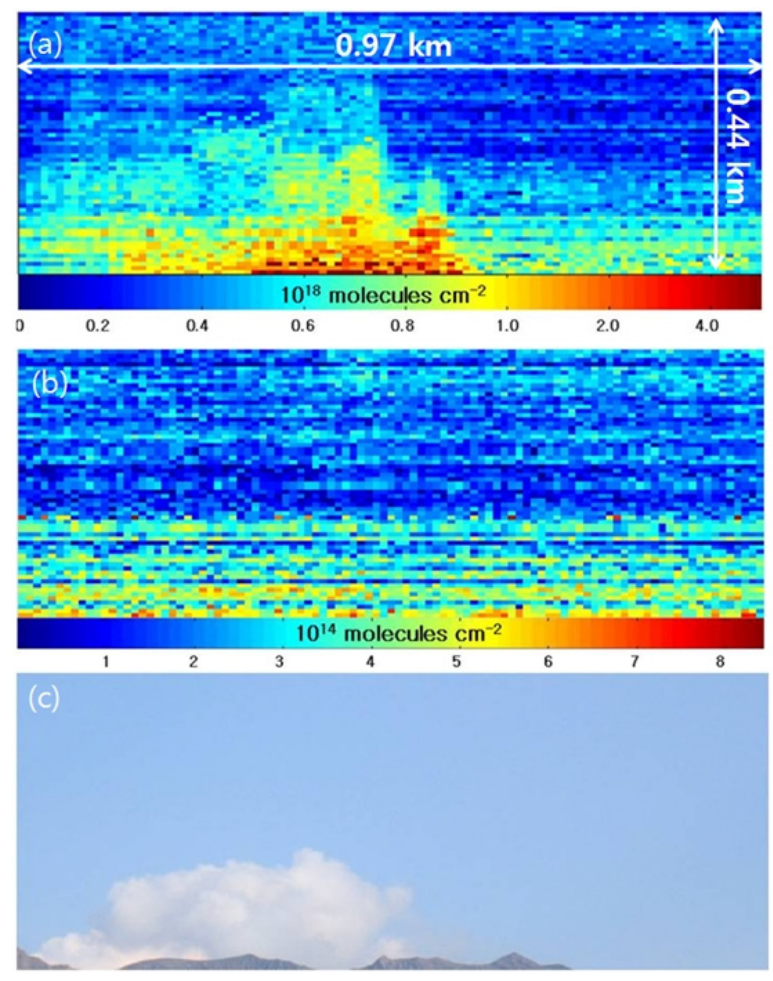

FIG. 5. Two-dimensional slant column density distributions of (a) $\mathrm{SO}_{2}$ and (b) $\mathrm{BrO}$ observed by the scanning imaging spectrograph system. (c) A Sakurajima volcanic crater RGB image was taken towards the system scanning direction at the measurement site during the measurement period.

TABLE 1. Sakurajima volcanic plume measurement parameters used by the scanning imaging spectrograph system

\begin{tabular}{cccccc}
\hline \hline Object distance & $\begin{array}{c}\text { The number of pixels } \\
(\text { vertical } \times \text { horizontal })\end{array}$ & $\begin{array}{c}\text { Image size } \\
(\text { vertical } \times \text { horizontal })\end{array}$ & $\begin{array}{c}\text { Pixel size } \\
(\text { vertical } \times \text { horizontal })\end{array}$ & Exposure time & $\begin{array}{c}\text { Total } \\
\text { measurement time }\end{array}$ \\
\hline $5.14 \mathrm{~km}$ & $100 \times 64$ & $0.44 \times 0.97 \mathrm{~km}$ & $6.8 \times 9.7 \mathrm{~m}$ & $1.1 \mathrm{~min}$ & $3.0 \mathrm{~min}$ \\
\hline
\end{tabular}



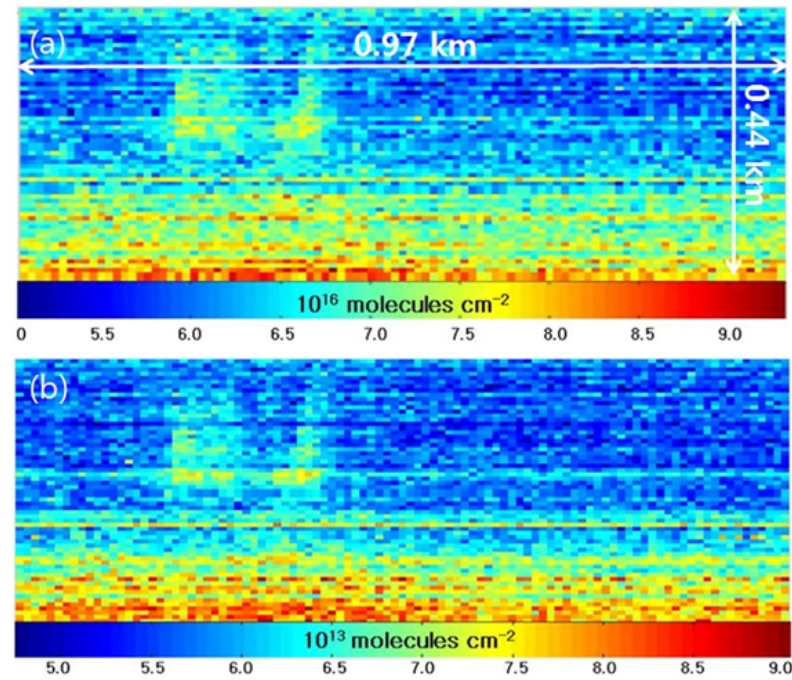

FIG. 6. Two dimensional fit error distributions in evaluating (a) $\mathrm{SO}_{2}$ and (b) $\mathrm{BrO}$.

instrument since the observed $\mathrm{BrO}$ SCD values increase as a function of elevation angle due to increased absorption light path lengths within a $\mathrm{BrO}$ layer. The $\mathrm{BrO}$ SCD measured during the campaign seems to represent their background level, which originates from the potential $\mathrm{BrO}$ sources at the measurement site such as the surrounding sea and preexisting volcanic plumes.

\section{CONCLUSIONS}

Spatially resolved $\mathrm{SO}_{2}$ and $\mathrm{BrO} \mathrm{SCDs}$ were retrieved from the spectra measured by a series of high spatial resolution vertical scans using an imaging spectrograph with a scanning device at the Sakurajima volcano, Japan. An image that shows the 2-D distribution of $\mathrm{SO}_{2}$ emitted from the Sakurajima volcanic crater was obtained at a distance of $5 \mathrm{~km}$ from the source location. $\mathrm{SO}_{2} \mathrm{SCD}$ values up to $4.5 \times 10^{18}$ molecules $\mathrm{cm}^{-2}$ were observed close to the top of the crater while the SCD values decreased with distance from the crater due to dilution with background air. However, background $\mathrm{BrO}$ SCD levels were measured only up to $8.4 \times 10^{14}$ molecules $\mathrm{cm}^{-2}$ during the measurement period. Though SCD information is useful to monitor atmospheric trace gases at a remote location where in-situ instruments can hardly reach, the absorption light path length information is required to convert SCD into volume concentration. Applications of chemical plume models or development of absorption light path length detecting devices will be needed for the quantitative investigation on the chemical evolution and transportation of trace gas species at their source sites.

\section{ACKNOWLEDGMENT}

This work was funded by the Korea Meteorological Administration Research and Development Program under Grant CATER 2006-3203.

\section{REFERENCES}

1. N. Bobrowski, G. Hönninger, B. Galle, and U. Platt, "Detection of bromine monoxide in a volcanic plume," Nature 423, 273-276 (2003).

2. C. K. Lee, Y. J. Kim, H. Tanimoto, N. Bobrowski, U. Platt, T. Mori, K. Yamamoto, and C. S. Hong, "High ClO and ozone depletion observed in the plume of Sakurajima volcano, Japan," Geophys. Res. Lett. 32 L21809, doi:10. 1029.2005GL023785 (2005).

3. N. Bobrowski, R. von Glasow, A. Aiuppa, S. Inguaggiato, I. Louban, O. W. Ibrahim, and U. Platt, "Reactive halogen chemistry in volcanic plumes," J. Geophys. Res. 112, D06311, doi:10.1029/2006JD007206 (2007).

4. N. Bobrowski and U. Platt, " $\mathrm{SO} 2 / \mathrm{BrO}$ ratios studied in five volcanic plumes," J. Volcanol. Geoth. Res. 166, 147-160 (2007).

5. J. H. Lee, T. S. Jang, H. S. Yang, and S. W. Rhee, "Optical design of a compact imaging spectrometer for STSAT3," J. Opt. Soc. Korea 12, 262-268 (2008).

6. J. H. Lee, C. W. Lee, Y. M. Kim, and J. W. Kim, "Optomechanical design of a compact imaging spectrometer for a microsatellite STSAT3," J. Opt. Soc. Korea 13, 193200 (2009).

7. F. Lohberger, G. Hönninger, and U. Platt, "Ground-based imaging differential optical absorption spectroscopy of atmospheric gases," Appl. Opt. 43, 4711-4717 (2004).

8. H. Lee, Y. J. Kim, and C. Lee, "Estimation of the rate of increase in nitrogen dioxide concentrations from power plant stacks using an imaging-DOAS," Environ. Monit. Assess. 152, 61-70, doi:10.1007/s10661-008-0296-4 (2008).

9. H. Lee, Y. J. Kim, J. Jung, C. Lee, K. P. Heue, U. Platt, M. $\mathrm{Hu}$, and T. Zhu, "Spatial and temporal variations in $\mathrm{NO}_{2}$ distributions over Beijing, China measured by imaging differential optical absorption spectroscopy," J. Environ. Manage. 90, 1814-1823, doi:10.1016/j.jenvman.2008.11.025 (2009).

10. U. Platt and J. Stutz, Differential Optical Absorption Spectroscopy, Principles and Applications (Springer Berlin, Heidelberg, Germany, 2008) doi:10.1007/978-3-540-75776-4.

11. R. L. Kurucz, I. Furenlid, J. Brault, and L. Testerman, "Solar flux atlas from $296 \mathrm{~nm}$ to $1300 \mathrm{~nm}$," National Solar Observatory, 1, NSO, Sunspot (1984).

12. D. J. Fish and R. L. Jones, "Rotational Raman scattering and the ring effect in zenith-sky spectra," Geophys. Res. Lett. 22, 811-814 (1995). 